\title{
Doctors and health funding must focus on most vulnerable: Philpott
}

\author{
— Cite as: CMAJ 2017 September 11;189:E1157-8. doi: 10.1503/cmaj.1095482
}

Posted on cmajnews.com on Aug. 21, 2017, and updated on Aug. 30, 2017.

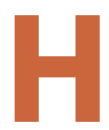
ealth Minister Dr. Jane Philpott announced something close to, but not quite, a national health accord in an Aug. 21 address to the Canadian Medical Association (CMA) General Council in Quebec City.

After months as the solitary holdout for a new pan-Canadian health funding agreement, Manitoba has conceded to take its share of $\$ 11$ billion in targeted federal funding. Over the next ten years, the federal government will provide Manitoba \$218 million to improve home and community care, $\$ 181.6$ million to support mental health and addictions initiatives, and an additional \$5 million to battle the province's disproportionately high rate of kidney disease.

With Manitoba on board, the federal government, provinces and territories have also agreed to a "common statement of principles" to hold provinces accountable for how they spend the funds, Philpott said. "We are committed to reporting on a set of pan-Canadian metrics so Canadians will know how we're doing in the areas of home care and mental wellness and where we all need to improve. Hold me to it, hold us to it."

Philpott described the multilateral agreement as a "big day for Canada." However, Manitoba Health Minister Kelvin Goertzen told reporters the agreements on targeted funds are "helpful but not transformative."

"They are not the answer to sustainability of health care and they are not a health care accord," he said in a press conference. Although mental health and home care are "significant, important issues," they only account for a "modest part of the overall health care budget."

Annual growth in federal health funding has dropped from $6 \%$ under the previ-

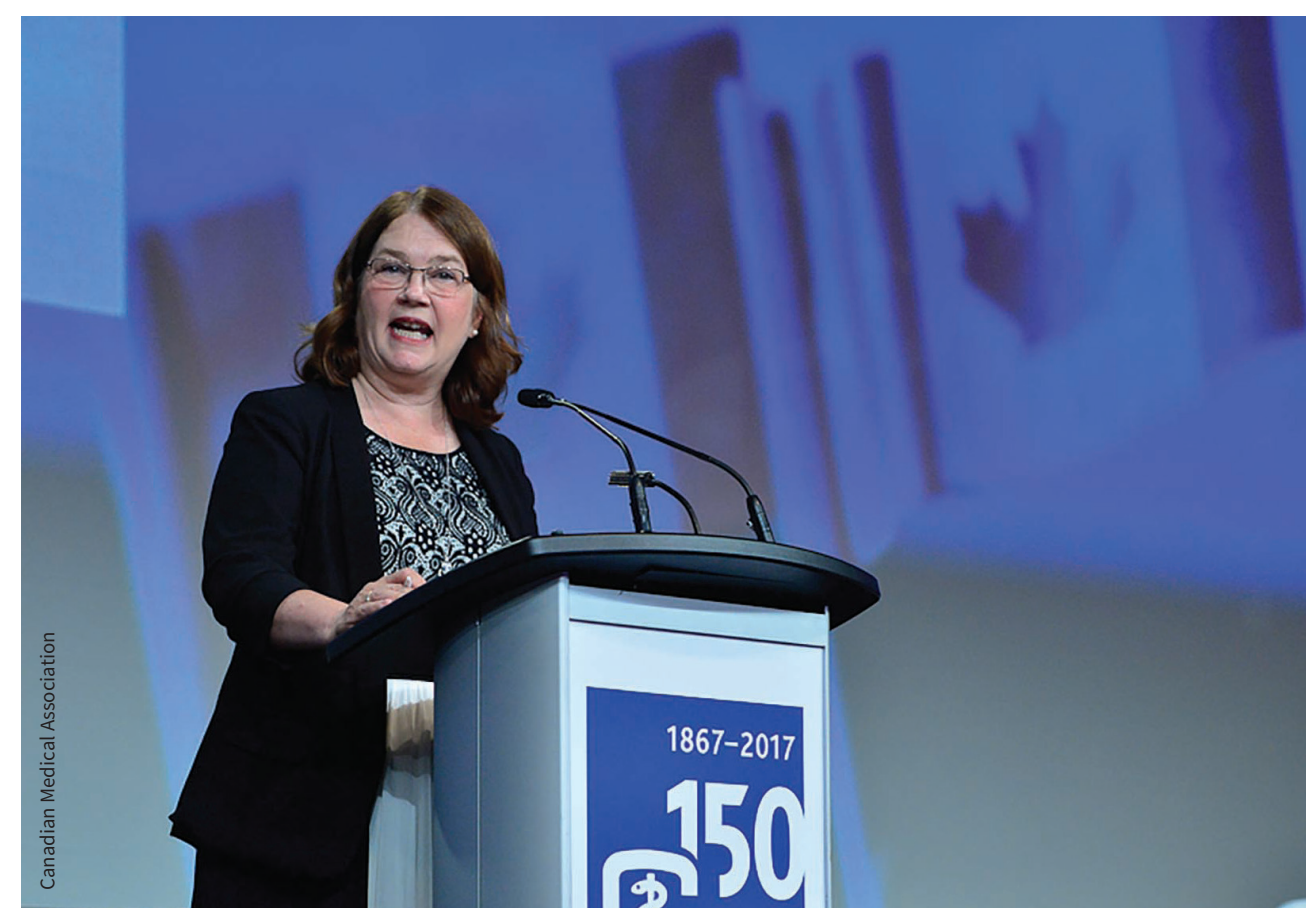

Federal Health Minister Dr. Jane Philpott addressed doctors at the Canadian Medical Association's 150th annual general council.

ous health accord to closer to $3 \%$ under the Liberal government. At this rate, federal contributions cover a smaller and smaller percentage of rapidly expanding costs, Goertzen said. "The federal government contribution to health care as it stands right now isn't sustainable."

In her remarks at CMA General Council, Philpott said the targeted investments set Canada on the path to "much stronger systems of primary care." She emphasized the importance of breaking down barriers to care for the most vulnerable, particularly Indigenous Canadians and people with addictions.

Although many doctors devote themselves to caring for marginalized people, "health systems are not actually designed to support or incentivize doctors who prioritize population health improvement including addressing the needs of vulnerable groups," she said.

Indigenous communities "have suffered from both negligence and systemic discrimination when it comes to healthcare," Philpott said. She argued that this presents the medical profession with an "opportunity and obligation to do better, and to do right," including by "growing a robust Indigenous health workforce."

Doctors also have a responsibility to stamp out stigma in health care that prevents people with addictions from seeking treatment, Philpott said. "Addiction is not a crime. Addiction is not a mark of moral failure. It is a health issue." She 
urged doctors to "work within your spheres of influence to promote the message that people who use drugs are people who do not need judgment."

In addition to individual action, Philpott also suggested there may be need for a "bold redesign of primary care," as well as "new fee structure or performance metrics that better incentivize care for the most vulnerable."
However, CMA president-elect Dr. Gigi Osler questioned how the federal government squares such suggestions with proposed tax reforms that would undercut physicians' financial security.

Philpott argued the reforms - which would eliminate certain tax benefits of incorporating - are an issue of fairness. "Even if we were to decide that doctors fall into a special category of society because of the costs of their education and they don't have pensions along with the vast majority of Canadian workers ... would it or does it make sense to create a system where some of you in the room can take advantage of legitimate tax rules... but the person sitting beside you is going to have pay much more tax?"

Lauren Vogel, CMAJ 